\title{
Lasers, a tool for soft cochleostomies
}

\author{
Andrew Fishman*, Laura Moreno, Arnold Rivera, Claus-Peter Richter \\ From 2nd Scientific Meeting of the Head and Neck Optical Diagnostics Society \\ San Francisco, CA, USA. 23-24 January 2010
}

Advancements in implantable auditory prostheses now demand preservation of residual auditory function following the surgery. Atraumatic cochleostomy formation is essential to this goal. Clinically reported hearing outcomes in human implantation are still quite variable in this regard. The objective of the study was to determine whether a $\mathrm{CO} 2$ laser operated with a handheld hollow waveguide can consistently produce cochleostomies without damaging the residual auditory function.

Human temporal bones were used to present a novel method creating a cochleostomy and adult guinea pigs were used to test whether cochlear function will be affected by the procedure. Baseline cochlear function was determined by recording compound action potential thresholds evoked by acoustic tone pips. Measurements were conducted at 6 steps per octave and 5 octaves starting at $50 \mathrm{kHz}$. The sound level as attenuated from 0 to $80 \mathrm{~dB}$ in steps of $5 \mathrm{~dB}$.

The human temporal bones were mounted and a standard approach through the facial recess was used to access the cochlea. The lateral bone was thinned at the basal turn with a motorized drill (Anspach Effort ${ }^{\circ}$, Palm Beach Gardens, FL, USA). Care was taken not to open the cochlea. The final opening of scala tympani was made with the handheld $\mathrm{CO} 2$ laser fiber (BeamPath ${ }^{\circ}$ OTO-S, OmniGuide ${ }^{\circ}$ Inc., Cambridge, MA, USA) and a Sharplan 20C CO2 laser (Lumenis ${ }^{\circ}$, Yokneam, Israel). In addition to describing the surgical approach, our experiments have demonstrated that for a careful selection of the laser's power, the safety range for the laser is superior to the safety range of drilling. Particularly important is the finding that multiple laser pulses through the same cochleostomy do not further increase the initial compound action potential (CAP) threshold elevation. Moreover, multiple laser pulses at different locations of the cochlea do not further increase the initial CAP

Northwestern University, Chicago, USA threshold elevation observed after the first laser pulse. When opening the inner ear, safe laser settings would be up to $4 \mathrm{~W}$, at pulse durations of $100 \mathrm{~ms}$ in single pulse mode.

Published: 29 October 2010

doi:10.1186/1758-3284-2-S1-O38

Cite this article as: Fishman et al.: Lasers, a tool for soft cochleostomies. Head \& Neck Oncology 2010 2(Suppl 1):O38.
Submit your next manuscript to BioMed Central and take full advantage of:

- Convenient online submission

- Thorough peer review

- No space constraints or color figure charges

- Immediate publication on acceptance

- Inclusion in PubMed, CAS, Scopus and Google Scholar

- Research which is freely available for redistribution

Submit your manuscript at www.biomedcentral.com/submit
C Biomed Central 